\title{
International credit and welfare: A paradoxical theorem and its policy implications
}

\author{
Kaushik Basu ${ }^{\mathrm{a}, *}$, Hodaka Morita ${ }^{\mathrm{b}}$ \\ ${ }^{a}$ Department of Economics, Cornell University, Ithaca, NY 14853, USA \\ ${ }^{\mathrm{b}}$ School of Economics, The University of New South Wales, Sydney, NSW 2052, Australia
}

Received 5 June 2003; accepted 25 April 2005

Available online 13 June 2005

\begin{abstract}
This paper considers a developing nation that faces a foreign exchange shortage and hence its demand for foreign goods is limited both by its income and its foreign exchange balance. Availability of international credit relaxes the second constraint. We develop a simple model of strategic interaction between lending institutions and firms, and show that the availability of international credit at concessionary rates can leave the borrowing nation worse off than if it had to borrow money at higher market rates. This 'paradox of benevolence' is then used to motivate a discussion of policies pertaining to international lending and the Southern government's method of rationing out foreign exchange to the importers.
\end{abstract}

(C) 2005 Elsevier B.V. All rights reserved.

JEL classification: L10; F30; O10

Keywords: Bank-firm interaction; Foreign aid; International credit; Welfare comparison

\section{Introduction}

There is a small literature that argues that the benefits of international credit do not accrue to the recipient developing country, ending up, instead, benefiting the

\footnotetext{
${ }^{*}$ Corresponding author. Tel.: + 16072552525 ; fax: + 16072552818 .

E-mail addresses: kb40@cornell.edu (K. Basu), h.morita@unsw.edu.au (H. Morita).
} 
donors or in the coffers of large corporations that sell goods to the developing country. ${ }^{1}$ The aim of this paper is to subject this claim to careful theoretical scrutiny. What we find is that, while this hypothesis need not always be true, there do exist parametric configurations under which it is valid. This is interesting because of its paradoxical nature. At first sight it seems that the availability of credit (or, more generally, availability of credit at better terms) cannot make the recipient, whether it be an individual or a nation, worse off because the recipient has the option not to take the credit or to pay a higher interest than what the donor demands (by, for instance, burning money). However, such simple logic runs into difficulty, especially in the domain of strategic international finance.

We construct a formal model and show that, when a nation buys goods from large corporations with monopolistic power, the availability of cheaper credit may actually leave the recipient worse off. In particular, a poor developing country that is currently borrowing money from a profit-maximizing international bank or financial institution may become worse off if some 'benevolent' organization steps in, in place of the profit-maximizing bank, and begins to lend hard currency at zero or a subsidized interest rate. Since public foreign lending is usually motivated by altruism and the need to fill in for market failures (Eaton, 1989, p. 1308) it seems quite surprising to find that there are situations where the recipient nation does better when it gets its foreign capital from private sources.

To see the logic, note that if a poor country has to borrow money from a profitmaximizing lender at an interest $i$ and pay a price $p$ to a manufacturer for the good, then (assuming the exchange rate is 1) the effective price on the margin is $(1+i) p$. Here the lender and the manufacturer compete in an interesting manner with the lender controlling $i$ and the manufacturer controlling $p$. Now suppose that a 'benevolent' lender steps in and sets the interest rate equal to zero, which reduces the effective price from $(1+i) p$ to $p$. The manufacturer takes advantage of this by raising its price from $p$ to $p^{\prime}$. On one hand, this price rise results in a welfare loss, since a part of the country's purchase is financed by its own foreign exchange. On the other hand, for the other part of the purchase that is financed by the lender, the country is still benefited from the benevolent lending because the effective price $p^{\prime}$ turns out to be still lower than $(1+i) p$. We demonstrate that the former disadvantage of the benevolent lending is greater than the latter advantage of it under a range of parameterization conditions.

In brief, this paper proposes a new game-theoretic framework for analyzing the strategic interaction between lending institutions and producers, and demonstrates the possibility of paradoxical reactions (which we call the 'paradox of benevolence'). In the process it draws attention to how we may want to reorganize international lending, paying particular attention to the market structure that the recipient country confronts, so as to ensure that the benefits reach their intended target.

\footnotetext{
${ }^{1}$ For works that either defend this proposition or debate it, see Winkler (1929), Hyson and Strout (1968), Bhagwati (1970), Gwyne (1983), Taylor (1985), Darity and Horn (1988), Basu (1991), and Deshpande (1999).
} 


\section{The factual context}

In this section we present a number of real-world contexts to which our theoretical framework is applicable, and explore the policy implications of our analysis, though the latter is picked up once again in Section 6.

One country lending money to another or giving aid with an eye on enhancing its own exports is not unusual at all. Many industrialized countries give loans to developing countries with the explicit requirement that the latter then use these to buy goods from the former (Eaton, 1989; Fleisig and Hill, 1984). Virtually all OECD countries have special provisions for providing export credit. This is money given to other nations specifically for those nations to buy goods from the donor nation. Moreover, importantly, a lot of this credit is given at concessionary rates, and, in particular, at lower than market interest rates. This is done, ostensibly, to help the recipient nations. Sweden, for instance, has the Swedish Export Credit Corporation or AB Svensk Exportkredit (SEK). This was established in 1962 "for the purpose of financing exports of Swedish capital goods and services on commercial terms" (OECD, 2001, Sweden p. 3). Up to 1978 SEK used to grant credit on strictly commercial terms. Since then there has been a program of subsidized lending. Subsidies are funded from Sweden's Development Aid Budget. As OECD (2001, Sweden p. 10) notes, "Concessionary credits are mainly tied to Swedish exports", though this is not necessarily so.

In USA, the Trade and Development Agency (TDA), formerly known as the Trade and Development Program (TDP), has two objectives - to give subsidized credit to help developing and middle-income countries and to promote the export of goods and services to those countries. In the US tied aid has legal authorization because the Trade and Development Act, 1983, in particular, its sections 644 and 645, explicitly authorize the Eximbank and USAID to provide tied aid and credit to other nations.

These are just two among many examples found in OECD (2001). There is reason to believe that the subsidized international credit sector, which aims to promote export and help the recipient country is substantial. As Fleisig and Hill (1984, pp. 322-323) noted, "Outstanding direct subsidized and export credits of the major lending countries (Canada, Italy, Japan, the United Kingdom and the United States) amounted to $\$ 55$ billion at the end of 1978. These lenders offered substantial subsidies, charging interest rates between 7 and $8 \%$, at the same time that private lenders charged between 5 and 15\%."

Under the requirement that the export credit should be used to import goods from the donor nation, the loan-recipient countries may be forced to choose a seller from a limited number of potential sellers. That is, the provision of export credit with such a requirement could end up creating or at least bolstering the sellers' market power. The paradoxical result of our model suggests that some of these recipient countries may have been better off if they were exposed to the private credit market with its non-concessionary lending.

There are accounts galore of countries that have received subsidized international credit but have adamantly remained basket cases. There are a number of reasons for 
this. The money may have been dissipated in consumption and not invested diligently; there may have been corruption and leakage at the level of the government. But, in addition, our model suggests that there may be another previously unexplored reason why the beneficiaries may not have done well. This is to do with an unholy alliance between subsidized credit and the market structure of firms and banks that confront the borrowing country. The money may have leaked out to international producers with market power. One implication of our model is that, when an export credit is offered to a country at a concessionary rate, it should be ensured that the recipient country uses the credit to import goods from competitive markets.

Our model also yields important implications for the organization of international lending by multilateral organizations, such as the World Bank and the IMF, that give subsidized credit. The IMF, for instance, provides financing to its member countries under different types of credit arrangements ("facilities"). These include regular facilities at market-related interest rates, and a concessionary facility for lowincome countries (the poverty reduction and growth facility, PRGF). PRGF arrangements cover a three-year period, with repayments over 5.5-10 years at an interest rate of $0.5 \% .^{2}$ See IMF (2001a) for further details on types of fund arrangements offered by the IMF.

A number of IMF-supported programs (in particular, practically all concessionary financing arrangements) have included a variety of structural conditionalities. Concerning trade-related conditionality, the IMF often requires trade liberalization measured by the trade restrictiveness index that combines the average level of tariff protection as well as the coverage of non-tariff barriers (IMF, 2001b). Our model indicates that the IMF should also keep an eye on the structure of the markets from which the borrower countries import goods. In particular, if a borrower country imports goods from industries with substantial market power, it may be better off by having to borrow from a non-concessionary facility rather than a concessionary facility, and so careful investigation is needed regarding the type of lending arrangement that is suitable. ${ }^{3}$

The model also highlights the crucial role of the mechanism through which the limited foreign exchange is released to the importers in the borrower country by the borrower government (or Central Bank). The paper suggests that the rules for allocating the limited foreign reserves followed by the government can make a crucial difference in determining what effect international credit or aid has on the well-being of the recipient nation. Hence the model, despite its use of a rather stylized framework, depicts theoretically the general idea explored empirically by Burnside and Dollar (2000) on how the nature of governance in the borrowing

\footnotetext{
${ }^{2}$ PRGF was established in 1999. The predecessors of the PRGF had been the structural adjustment facility (SAF) and the enhanced structural adjustment facility (ESAF).

${ }^{3}$ There is now a lot of evidence from cross-country studies on how trade liberalization and greater openness in general leads to the growth of income (see, for instance, Ben-David, 1993; Sachs and Warner, 1995; Frankel and Romer, 1999). What we show is that, if the trade liberalization and openness leads to a more competitive trade environment as one may expect, then this may also increase the efficacy of the concessionary facility offered by the IMF.
} 
nation can critically determine whether aid (or subsidized international lending) will work to its advantage or not. ${ }^{4}$

As a final point, we discuss an application of our theoretical framework to intracountry rural credit markets. In rural regions of developing countries, peasants often face short-term money shortage in the pre-harvest season. Hence, borrowing is widespread in such times with repayment occurring after the harvest when the peasant regains liquidity. According to a large-scale survey of contractual relationships in rural India (see Bardhan, 1984, Chapter 9, for details), landlords often lend money to their own share tenants, where the loans can be for many different purposes-consumption to tide over the lean season or production purpose loans. Interestingly, Bardhan reports that these loans can often be without interest. If such a peasant faces a monopolistic product market from which he buys the goods that he needs, then our theoretical framework suggests that the paradoxical result can occur. ${ }^{5}$ That is, such a peasant could be better off if he were exposed to a profitmaximizing money lender rather than to a 'benevolent' money lender. In this context, government subsidized credit to poor peasants may not be the panacea that it is often made out to be.

\section{The model}

In this model there is a developing country-henceforth South, and an industrialized country-henceforth North. These countries have their own currencies but for all inter-country trade and exchange the only acceptable currency is the North's currency. This is the 'hard' currency. We shall refer to the South's currency as the 'soft' currency.

The South, in our model, has a shortage of 'hard currency'. This is so in the sense that if it could buy more hard currency at the going exchange rate it would do so and use it to buy more foreign goods. The fact of a country facing a shortage of hard currency suggests some rigidity in the exchange rate. We treat the exchange rate as fixed and, without loss of generality, we treat it as fixed at 1 . Although one reason for making this assumption is to make the model tractable, we also feel that this is not as strong an assumption as may appear at first sight. The fact that many Third World nations do face a shortage of hard currency, suggests that exchange rates are at least partially rigid in reality. We suspect that there are innate factors in the structure of international economic relations which cause this. How else can one explain why, even after developing country governments go for a free float and allow the exchange rate to be market driven, shortages of hard currency persist?

\footnotetext{
${ }^{4}$ See also Collier (1997) and Hansen and Tarp (2001).

${ }^{5}$ It is plausible that poor peasants often buy goods from sellers with substantial market power. Bardhan (1984) argues that highly personalized ties between transacting agents that are typically observed in isolated rural villages often result in monopolistic power. See Bhaduri (1983) for a similar argument regarding 'personalized rural market'.
} 
Another assumption in this paper concerns the modeling of the developing country government. We treat the government not as a strategic agent, nimbly maximizing some payoff, but as a somewhat mechanical bureaucracy which has some rigid rules, to which it adheres. In particular, we model licensed importers in the South, to which the government (or the Central Bank) allocates its limited foreign exchange balance; and they are given the right to buy goods abroad and sell them in the South. One reason why we treat the government as not a strategic agent is for tractability; the model has a surfeit of strategic agents. However, we also believe that this description is fairly realistic in the case of many developing and transition economies. For instance, in the case of Pakistan and India, it fits reality quite well especially through the seventies and eighties. ${ }^{6}$

We shall in this paper focus on one good, which the South likes to consume but it does not produce. The good is in fact produced by a firm based in the North, which sells the good (not only in the North but also) in the South through the licensed importers. The Northern firm produces the good at a constant marginal cost $c$, faces no fixed cost, and chooses the price $p$ at which it sells to the South. Though in our formal model we work with one such firm, our qualitative results would be unchanged under $n$ oligopolistic firms.

On the demand side we assume, without loss of generality, that the South has one consumer, who is a price taker. Imagine first that the consumer has free access to the hard currency at the going exchange rate. In such a case let the consumer's inverse demand function for the good sold by the North be given by

$$
p=a-b x,
$$

where $a>c, b>0$, and $p$ is the price of the product and $x$ the amount demanded. This will be called the unconstrained demand curve. Without a shortage in hard currency and in the absence of licensed importers (that is, assuming that the consumers buy directly from the Northern producers), standard monopoly analysis shows the equilibrium price and quantity to be

$$
p^{*}=\frac{a+c}{2} \text { and } x^{*}=\frac{a-c}{2 b} .
$$

This point is illustrated in Fig. 1 by the point $E^{*}$. Note that the total amount of hard currency needed to buy the equilibrium amount of the good is given by $p^{*} x^{*}=\left(a^{2}-c^{2}\right) / 4 b$.

We shall from here on consider the case in which the South's foreign exchange reserve $R$, though positive, is insufficient for this point $E^{*}$ to be attained. In other words, we are making the following assumption.

\section{Assumption 1.}

$$
0<R<\left(a^{2}-c^{2}\right) / 4 b .
$$

\footnotetext{
${ }^{6}$ Writing in the very early nineties on Pakistan, Baysan (1992, p. 468) observed, "Distinct from import bans and restrictions, value limits on individual licenses against cash for imports of machinery and millwork have been (and still are being) maintained .... These ceilings ... function as nontariff barriers ... and serve as a nonprice rationing mechanism for the allocation of foreign exchange."
} 


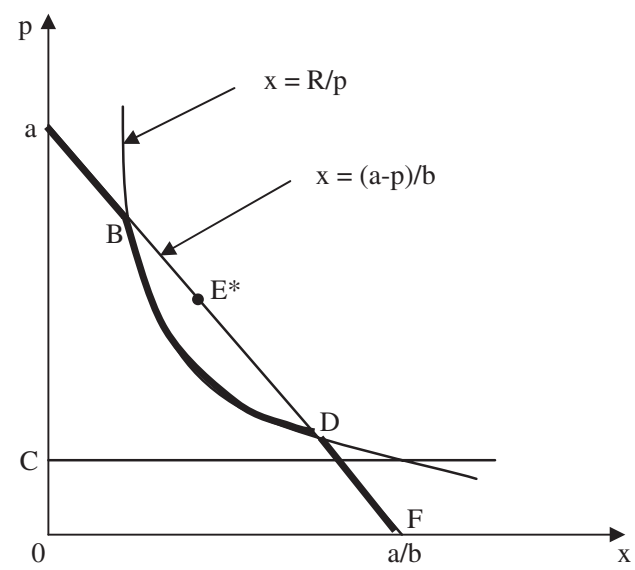

Fig. 1.

That is, the shortage of hard currency is such that the Northern firm cannot fully capture the monopoly rent associated with the unconstrained demand curve.

It is being assumed here that, what the South suffers from is not a problem of insolvency but illiquidity. In other words, it expects to have adequate access to foreign exchange in the future. The simplest way to make this formal is to suppose that the South's currency becomes convertible in the future. So in the future its demand is not constrained by its foreign exchange reserves. We will assume that this foreign-exchange constrained position lasts for one period (which can of course be very long) and it is this one period that our model studies.

So the Southern government has a reserve of $R$ units of hard currency. How does the government use this? We will assume that the government sets a quota for each of the $m(\geqslant 2)$ importers. That is, each importer is given the right to acquire foreign exchange up to this quota limit by giving up an equivalent amount of soft currency. With this foreign exchange the importers use the hard currency to buy goods from the North which they then sell to the Southern consumers. We shall, for simplicity, assume that all importers are treated identically, and so each importer has access to $R / m$ units of the hard currency. It will be assumed that the importers take the international price of the product as given and constitute a Bertrand oligopoly in the domestic market.

It will be shown later in Section 5 that, for the purpose of our analysis, such a model works the same way as an alternative model in which the Southern government gives consumers direct access to a fixed amount of foreign exchange. Given this mathematical equivalence, in what follows we proceed with our analysis by supposing that the Southern government announces that the consumer can acquire up to $R$ units of hard currency. In other words, the amount of foreign good, $x$, that the consumer buys must satisfy

$$
x \leqslant R / p .
$$


Keeping in mind that (1) implies that the demand function (with no foreign exchange constraint) is given by $x=(a-p) / b$, and combining this with (2) we see that the actual demand function of the South is given by

$$
x=\min \left\{\frac{a-p}{b}, \frac{R}{p}\right\} .
$$

This is demonstrated by the thick line in Fig. $1 .^{7}$

We now incorporate international lending into our model; we will consider the following two cases:

Case I. There is a non-profit 'international organization' that lends hard currency credit to the South at a subsidized interest rate.

Case II. There is a profit-maximizing international bank (based in the North) that gives hard-currency credit to the South.

We shall, throughout, assume, without loss of generality, that the interest rate prevailing in the North is zero. The Southern consumer and government do not have direct access to the Northern credit market, but the international organization and the Northern bank have access to it. So to these latter agents the opportunity (interest) cost of lending money to the South is zero. Given our focus on illiquidity (rather than insolvency) problems faced by the South, we assume that the South never defaults.

The analysis of Case I is straightforward. Let us suppose that the international organization lends to the South at the opportunity cost interest, that is, an interest rate of zero. Once South has access to such credit, the foreign exchange constraint of $R$ becomes immaterial. South's demand for the product is given by Eq. (1) and the equilibrium price and quantity are given by $p^{*}$ and $x^{*}$, which are represented by point $E^{*}$ in Fig. 1.

Case II is the interesting case, and what we go on to show, later, is that the Southern country may be better off in this case than under Case I. But first we need to depict the equilibrium that will arise in Case II.

Since the central issue in the analysis of Case II is the strategic interaction between the firm and the bank, we derive the reaction functions (more precisely 'implicit reaction functions') of the firm and the bank and then characterize Nash equilibria. Let us start with the firm. Consider first the case where $R=0$, that is, for whatever the South buys from the North it has to first borrow money from the bank.

In Fig. 2, $a F$ is the South's unconstrained demand curve (given by Eq. (1)). Suppose the bank charges an interest rate of $i$. Then if the firm charges a price of $p$, the effective price to the Southern consumer is $(1+i) p$. Hence the effective demand

\footnotetext{
${ }^{7}$ If we were thinking of this as an intra-country, credit market problem, we could think of consumers who have a 'true' demand curve (i.e., in the absence of any liquidity problems) given by (1) but have little liquid cash, maybe because this is the pre-harvest, lean season. If the liquid cash available with the consumer is given by $R$, then his effective demand function for the good in questions is given by (3).
} 


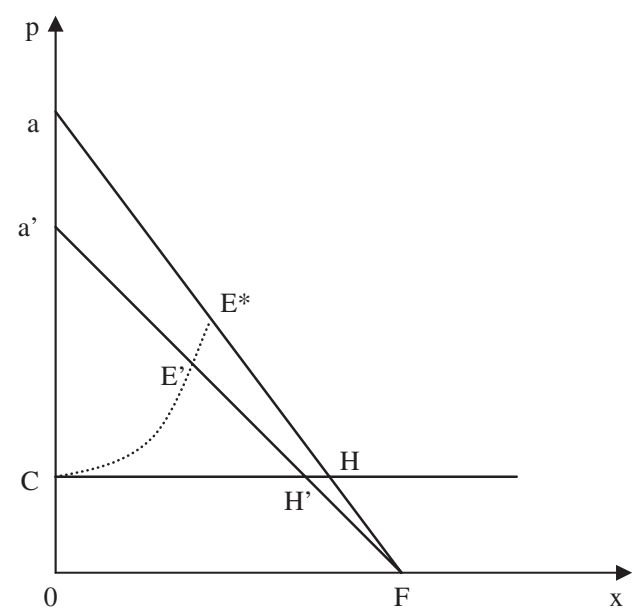

Fig. 2.

curve is given by the line $a^{\prime} F$ where $O a=(1+i) O a^{\prime}$. Standard monopoly analysis implies that the firm's best response is to choose a price that is represented by the midpoint of line segment $a^{\prime} H^{\prime}$, shown by point $E^{\prime}$. By considering different interest rates, $i$, and plotting the mid-point that represents the firm's best response for each $i$, we obtain the firm's best response curve. This is represented by the broken line $E^{*} E^{\prime} C$. We call it the firm's 'implicit reaction function. ${ }^{8}$ The reader should also check that, if $c$ were 0 , the firm's implicit reaction function would be a vertical line from $E^{*}$ down to the horizontal axis. The reason why we call this an 'implicit' reaction function is because, unlike in a conventional reaction function where the two variables chosen by the two players are represented on the two axis, here the interest rate $i$, chosen by the bank, is not represented on any axis, but is implicit in the effective demand curve.

Now let us bring in the fact that $R>0$, as shown in Fig. 3. If the interest rate, $i$, charged by the bank is such that the effective demand curve is $a^{\prime} F$, then the actual demand curve (the one which takes into account the fact that up to $R$ units, the South does not need to borrow money) is given by the thick line, going through points $B$ and $D$. The firm's implicit reaction function is $E^{*} K^{\prime}$ and point $B$, where $E^{*} K$ is a truncated segment of the $E^{*} E^{\prime} C$ curve in Fig. 2. To see this, gradually increase the value of $i$, starting from $i=0$. The firm's best response is represented by point $E^{*}$ when $i=0$, and by point $E^{\prime}$ (see Fig. 2) when $i$ is positive but sufficiently small. Then, as $i$ rises $E^{\prime}$ moves in the southwest direction. But before $E^{\prime}$ reaches point $K$ (in Fig. 3, the firm's best response point will jump to point $B$. Let us denote by $K^{\prime}$ the point where the jump occurs. To see that this will happen, suppose that $i$ is such that the line, $a^{\prime} F$, passes through point $K$ in Fig. 3. Clearly, the firm is strictly better off

\footnotetext{
${ }^{8}$ The mathematical properties of this function are spelled out in Anant et al. (1995).
} 


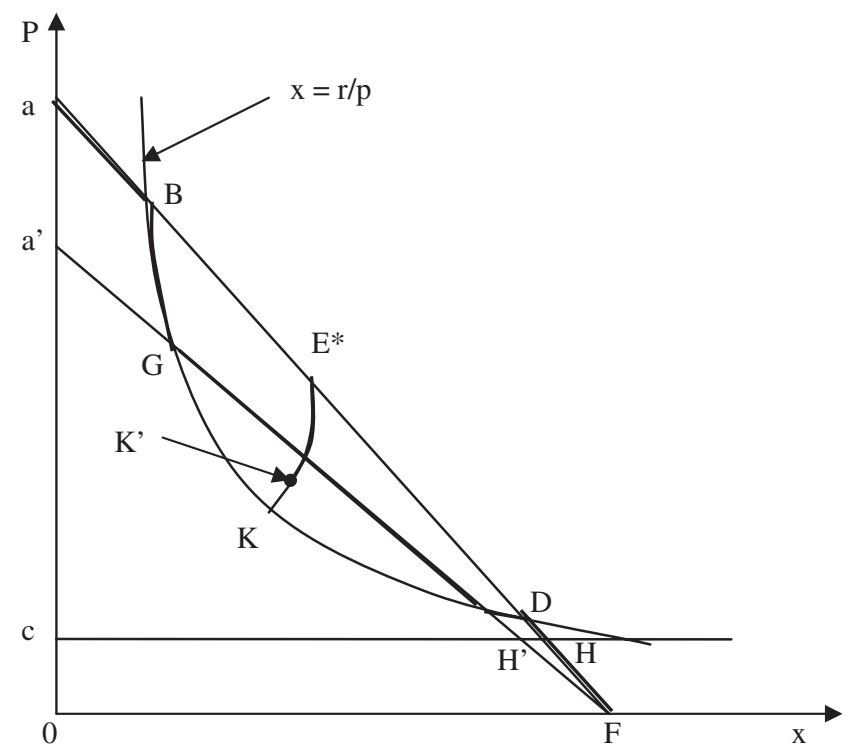

Fig. 3.

by choosing the price that corresponds to point $B$ rather than point $K$; since at both prices revenue is the same and the total cost is smaller at point $B$. Hence, there exists point $K^{\prime}$, where the firm is indifferent between choosing point $K^{\prime}$ and point $B$.

Now we turn to the bank's reaction function. First suppose that the firm has fixed a price, $p$, such that $R / p \geqslant(a-p) / b$ holds. In this case, the South does not borrow hard currency because the consumer's demand given by the unconstrained demand curve (i.e., $p=a-b x$ ) is feasible without borrowing any hard currency. Then, any value of $i$ is the bank's best response, because the bank cannot make any profits from lending to the South, for all $i \geqslant 0$.

Next suppose that the firm has fixed a price, $p$, such that $R / p<(a-p) / b$ holds. This condition means that, under the price, the consumer's demand given by the unconstrained demand curve is not feasible without borrowing hard currency because the Southern government has only $R(>0)$ units of hard currency. Graphically, the price is strictly between the prices represented by point $B$ and $D$ in Fig. 3. Given such price, the bank can make a profit from lending hard currency to the South, which is given by

$$
\pi_{B}(i) \equiv i\left\{p\left[\frac{a-p(1+i)}{b}\right]-R\right\} .
$$

Graphically, the bank's profit is represented by area QRST in Fig. 4, where the firm has fixed a price at $p=p^{\prime}$ and the bank has chosen $i$ represented by $a^{\prime} F$. Given $p^{\prime}$, the bank chooses $i$ so that the area QRST is maximized. The maximization implies that 


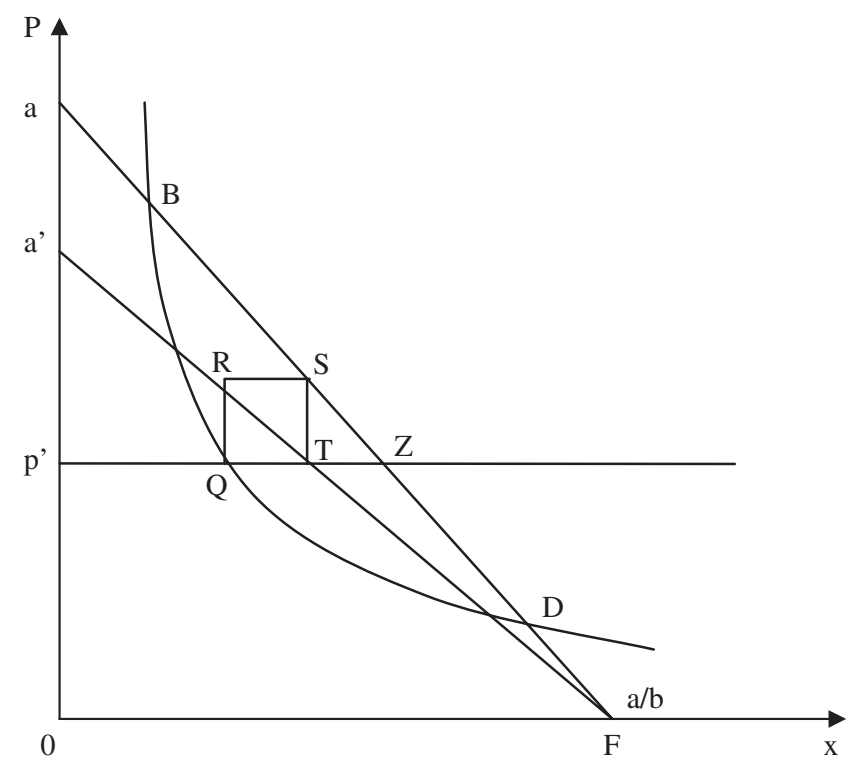

Fig. 4.

the bank chooses $i$ such that point $T$ in Fig. 4 becomes the mid-point of $Q Z$. Then, for any given $p^{\prime}$, the bank's best response is to choose $i$ such that corresponding $a^{\prime} F$ line goes through the mid-point of $Q Z$. Plotting such mid-points for different values of $p^{\prime}$, we obtain the broken line in Fig. 5. We call it the bank's 'implicit reaction function.'

We are now ready to identify Nash equilibria. Superimpose the firm's implicit reaction function $\left(E^{*} K^{\prime}\right.$ in Fig. 3) here. A Nash equilibrium is depicted by the point of intersection of the two reaction functions, shown here by point $N$, where the equilibrium price is given by $\hat{p}$ and the interest rate is the one implicit in the effective demand curve $a^{\prime} F$. This is an equilibrium in which a positive amount is borrowed. We call this the $N$-equilibrium. Note that the $N$-equilibrium does not always exist because the broken line does not necessarily intersect with $E^{*} K^{\prime}$. Note also that there exists another Nash equilibrium, where the firm chooses the price that corresponds to point $B$ and the bank chooses a very high interest rate. This is an equilibrium in which no lending occurs.

\section{The paradox of benevolence}

We now demonstrate that the paradox of benevolence can happen in the $\mathrm{N}$ equilibrium. The aggregate welfare earned by the South in the $N$-equilibrium is shown in Fig. 6 as the area $S T Q \hat{p} a$. 


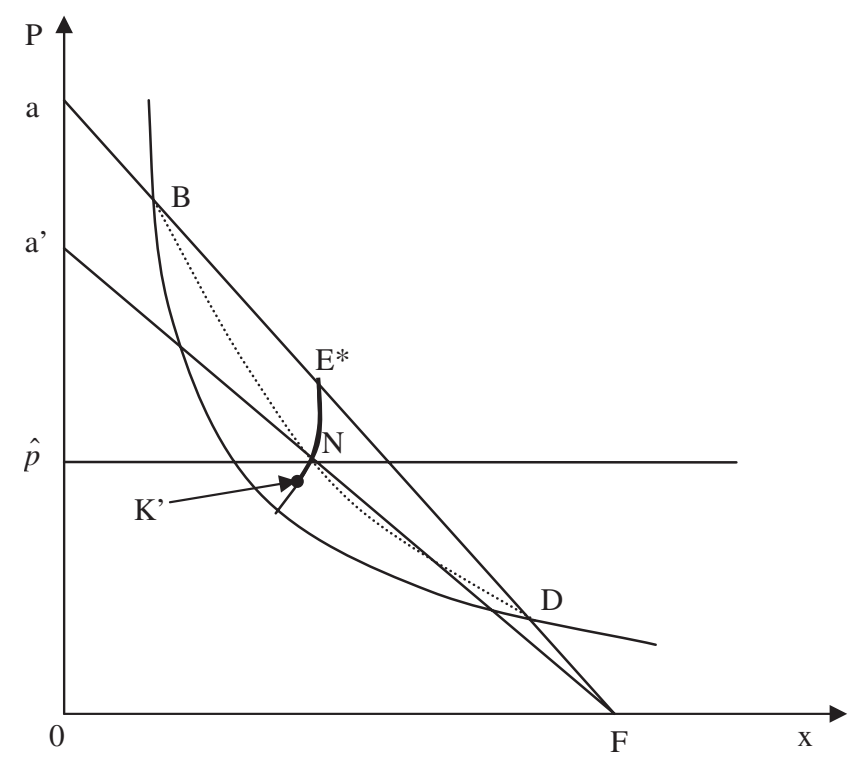

Fig. 5.

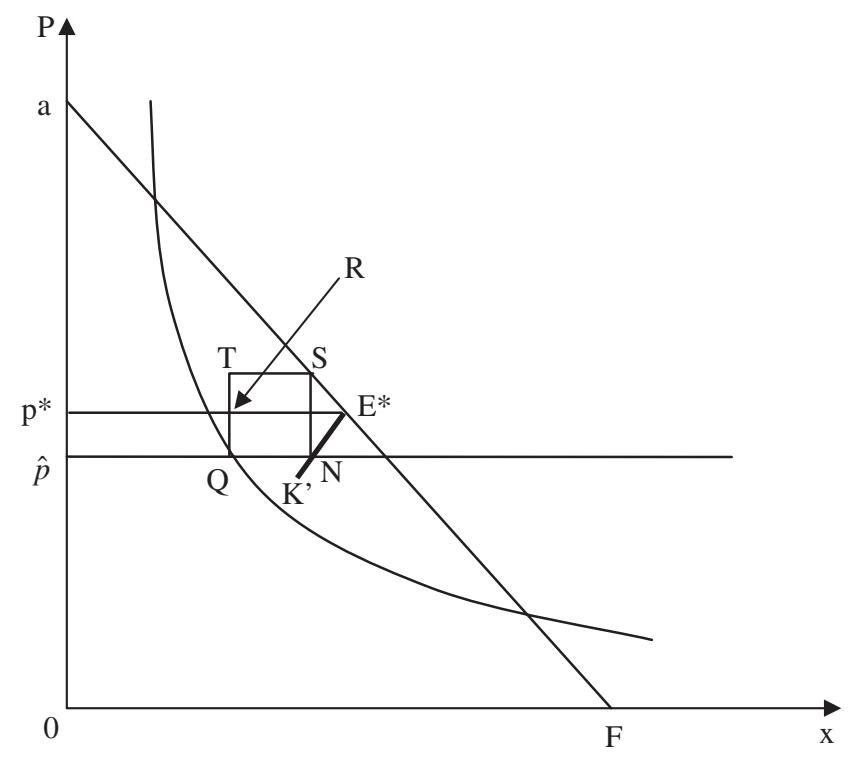

Fig. 6.

Let us call this, in brief, $W^{\pi}$, where the $\pi$ is a reminder that this is the welfare of the South when the lender of credit is a profit maximizer. Let us denote South's aggregate welfare when the Northern lender is benevolent (and charges no interest) 
by $W^{b}$, where $b$ is for benevolence. Our claim is that there are parameters of the model where

$$
W^{b}<W^{\pi}
$$

We will say that the 'paradox of benevolence' occurs if this inequality is true.

To prove this we need to first depict $W^{b}$. Recall that when the South can freely borrow from a benevolent lender (Case I, above) equilibrium occurs at point $E^{*}$ and the price of the Northern good is given by $p^{*}$. Hence $W^{b}$ is the area of $a E^{*} p^{*}$. By examining Fig. 6 it is clear that a priori we cannot say which is larger $W^{b}$ or $W^{\pi}$. Now, we are able to state the central result of the paper.

Proposition 1 (The paradox of benevolence). For any parameter values that satisfy Assumption 1, there exists a value $\tilde{c}(>0)$ such that, holding all parameter values except $c$ fixed, the model exhibits the following property for all $c \in[0, \tilde{c}]$ :

The $N$-equilibrium exists and the paradox of benevolence occurs in that equilibrium.

Proof. See Appendix A.

To understand the logic behind the result, let us compare the Northern firm's profit maximizing behavior in Case I and Case II. Let $M R(p, x)$ denote the Northern firm's marginal revenue when it sells $x$ units of the good to the South at the price of $p$. In Case I, the international organization lends to the South at the interest rate $i=0$, and the Northern firm sells $x^{*}$ units of the good at the price of $p^{*}$ so that the marginal revenue becomes equal to the marginal cost, i.e., $\operatorname{MR}\left(p^{*}, x^{*}\right)=c$. In Case II, the profit-maximizing international bank charges $i>0$. Given the shortage of hard currency in the South, the positive interest rate reduces the South's willingness of pay, which in turn reduces the Northern producer's marginal revenue. In order to sell $x^{*}$ units to the South, the Northern producer can now charge only $[1 /(1+i)] p^{*}$, where $\operatorname{MR}\left([1 /(1+i)] p^{*}, x^{*}\right)=[1 /(1+i)] M R\left(p^{*}, x^{*}\right)$.

First consider the case where the marginal cost $c$ is zero. Then, in Case I, under the Northern firm's optimal choice $\left(p^{*}, x^{*}\right)$ its marginal revenue $M R\left(p^{*}, x^{*}\right)$ is zero. In Case II, although the positive interest rate reduces the South's willingness to pay, the Northern firm's marginal revenue when it sells $x^{*}$ units is unaffected and still zero (that is, $\operatorname{MR}\left([1 /(1+i)] p^{*}, x^{*}\right)=[1 /(1+i)] M R\left(p^{*}, x^{*}\right)=0, \quad$ if $\left.\quad M R\left(p^{*}, x^{*}\right)=0\right)$. Hence, the Northern firm's optimal quantity is $x^{*}$ in Case II as well as in Case I. That is, the interest rate charged in Case II does not result in any additional quantity distortion. On the other hand, the Northern firm must reduce its price from $p^{*}$ to $[1 /(1+i)] p^{*}$ to sell $x^{*}$ units. And, given the positive amount of the South's foreign reserve $(R>0)$, the South gets some benefit from the lower price charged by the Northern firm. The result is that the South is strictly better off in Case II (i.e., the paradox of benevolence occurs) when $c=0$.

Now let the marginal cost $c$ be strictly positive, so that $\operatorname{MR}\left(p^{*}, x^{*}\right)=c>0$ holds under the Northern firm's optimal choice $\left(p^{*}, x^{*}\right)$ in Case I. In Case II, the South's lower willingness to pay now implies that the Northern firm's marginal revenue when it sells $x^{*}$ units is strictly below the marginal cost $c$ (that is, $\left.\operatorname{MR}\left([1 /(1+i)] p^{*}, x^{*}\right)=[1 /(1+i)] M R\left(p^{*}, x^{*}\right)<c\right)$. This results in an additional 
quantity distortion; that is, the Northern firm's optimal quantity in Case II (denoted $\hat{x}$ ) is now strictly less than $x^{*}$. However, when the marginal cost $c$ is small, the degree of this distortion is small. Then, this negative impact on the South's welfare is more than offset by the benefit of the lower price, and hence the South is strictly better off in Case II when $c$ is small enough. This is what the Proposition states.

The result can also be understood graphically. First let $c=0$. Then, as we have already seen, the firm's implicit reaction function is a vertical line from $E^{*}$. Hence, as shown in Fig. 7, the $N$-equilibrium point, $N$, is now vertically below $E^{*}$. Since the Northern firm's optimal quantity is $x^{*}$ in Case II as well as in Case I, the South can capture area $a E^{*} p^{*}$ (which is the South's consumer surplus in Case I) as a part of its consumer surplus in Case II. In addition, due to the lower price charged by the firm, the South also captures area $T Q \hat{p} p^{*}$ as its consumer surplus. The result is that the South's consumer surplus in Case II, represented by area $E^{*} T Q \hat{p} a$, is greater than its consumer surplus in Case I, represented by area $E^{*} p^{*} a$. Now let $c>0$. Then, as shown in Fig. 6, the $N$-equilibrium point, $N$, is not vertically below $E^{*}$ anymore, and the firm's optimal quantity is $\hat{x}$, where $\hat{x}<x^{*}$. This additional quantity distortion in Case II reduces the South's consumer surplus. However, if $c$ is relatively small, area $S E^{*} R T$ is smaller than area $R Q \hat{p} p^{*}$, which implies that the South is still better off in Case II than in Case I.

We conducted numerical simulations to compute the zones of paradox in the $(R, c)$-space, in particular, a space in which the horizontal axis represents $R$ and the

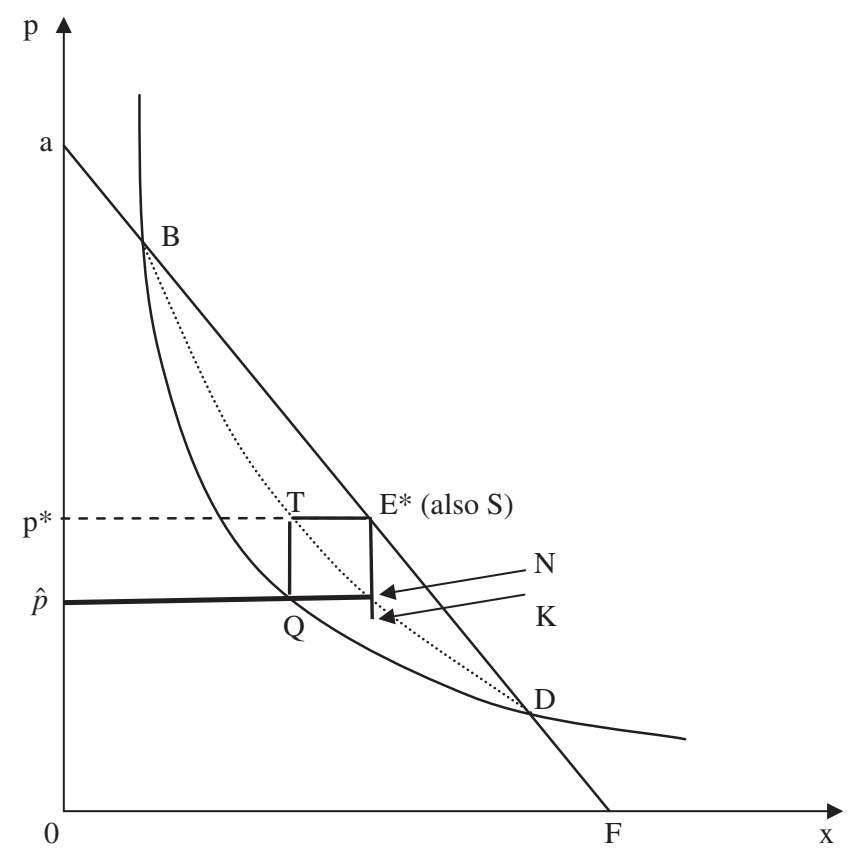

Fig. 7. 
Table 1

Numerical examples for the paradox of benevolence (The value of $c^{\max }$ when $a=10$ )

\begin{tabular}{lll}
\hline$R$ & $b=0.4$ & $b=0.5$ \\
\hline 5 & 0.94 & 1.22 \\
10 & 2.23 & 3.22 \\
15 & 7.00 & 6.29 \\
20 & 6.06 & 5.16 \\
25 & 5.16 & 4.16 \\
30 & 4.35 & 3.31 \\
35 & 3.63 & 2.57 \\
40 & 3.00 & 1.91 \\
45 & 2.44 & 1.23 \\
50 & 1.91 & - \\
55 & 1.37 & - \\
60 & 0.73 & - \\
65 & - & - \\
\hline
\end{tabular}

vertical axis represents $c$. For each value of $R$ we have computed the maximum value of $c$, denoted $c^{\max }$, such that the paradox occurs for all non-negative values of $c$ less than $c^{\max }$. The computation is made for the case where $a=10$ and $b=0.4$ or 0.5 and the results are displayed in Table 1 . The table tells that, for instance, with $b=0.4$, we have $c^{\max }=2.23,6.06$, or 3.00 , when $R=10,20$, or 40 , respectively. Namely, the Paradox of Benevolence occurs for all $c \in[0,6.06]$ when $a=10, b=0.4$ and $R=20$. Note that $c<a$ (=10 in these examples) must hold for the Northern firm to sell a positive amount of goods to the South. The numerical examples therefore seem to indicate that the paradox of benevolence occurs in non-trivial ranges of parameter values.

It is interesting to note the table exhibits an "inverted-U" shape in the $(R, c)$-space. That is, holding other parameter values fixed, the value of $c^{\max }$ is increasing in $R$ when the value of $R$ is relatively small, and it is decreasing in $R$ when the value of $R$ is relatively large. Although we have worked out a number of examples and identified this property in all of them, we have been unable to prove that this is the general property.

\section{Competition among licensed importers}

In Section 3 we began with the realistic assumption that, in the South, the government gives some designated importers the right to acquire hard currency from the central bank in order to import goods for domestic sale. We then pointed out that, if these importers took the international price, $p$, of the good and the interest rate, $i$, as given, and chose the domestic sale price (that is, they played a Bertrand game), we could ignore these importers for the purpose of our analysis. Given this, we derived our result under the assumption that government allocated foreign 
exchange directly to the consumers rather than to the designated importers. In this section we show that we can indeed ignore the importers in order to derive our results.

As before, the Southern demand for the Northern good is given by

$$
x=\frac{a-r}{b}
$$

where $r$ is the price that the consumers have to pay. There are now $m$ identical importers. They can buy the good (subject to having the requisite foreign exchange) from a Northern producer at a price, $p$, chosen by the Northern producer. It is assumed that the Southern importers take this price as given. Each of these importers is given access to $R / m$ units of foreign exchange by the Southern government. If they want more foreign exchange they have to borrow this from a Northern bank at an interest rate of $i$. Hence, if an importer wants to buy $x$ units of this good from the North it has to incur a total cost, $T C(x)$, given by

$$
T C(x)= \begin{cases}p x & \text { if } p x \leqslant \frac{R}{m}, \\ \frac{R}{m}+(1+i) p\left(x-\frac{R}{m p}\right) & \text { if } p x>\frac{R}{m} .\end{cases}
$$

Now, each of these $m$ importers have to choose a price at which it offers to sell the product to the Southern consumers. If $r_{i}$ denotes the price offered by importer $i$, then we may denote the strategy $n$-tuple of the $m$ importers by

$$
\left(r_{1}, \ldots, r_{m}\right) \text {. }
$$

The profit earned by importer $i$ may then be denoted by $\pi_{i}\left(r_{1}, \ldots, r_{m}\right)$.

Our aim is to characterize the Nash equilibrium (Bertrand equilibrium in this case) of this game. We will in particular be interested in the symmetric Nash equilibrium. In other words, we define $r^{*}$ to be an 'equilibrium' if, for all $i=1, \ldots, m$, $\pi_{i}\left(r^{*}, \ldots, r^{*}\right) \geqslant \pi_{i}\left(r^{*}, \ldots, r_{i}, \ldots, r^{*}\right)$, for all $r_{i}$.

Fortunately, to characterize such an equilibrium we do not need to fully characterize the $\pi_{i}$ function. We will here make the following reasonable assumptions. If every importer charges the same price $r$, then each importer faces a demand of $(a-r) / b m$. If all importers, excepting importer $i$, charge $r$ and importer $i$ charges $r_{i}(\neq r)$, then the consumers respond as follows. If $r_{i}<r$, importer $i$ faces a demand equal to $\left(a-r_{i}\right) / b$. All consumers who fail to buy from $i$, direct their demand at price $r$ to the other importers. If $r_{i}>r$, all consumers go to importers other than $i$. Only those with unmet demand turn to $i$. These are fairly usual assumptions; a formal statement of these occur in Basu (1993).

Let us now suppose that the firm has fixed a price, $p$, such that $R / p<(a-p) / b$ holds. Also suppose that the bank has fixed an interest rate, $i$, such that $R / p<(a-$ $p(1+i)) / b$ holds. This condition means that, if government allocated foreign exchange directly to the consumers, then the consumers' demand given by the unconstrained demand curve is not feasible without borrowing hard currency and so they borrow a positive amount of hard currency from the bank. Under such $p$ and $i$, 


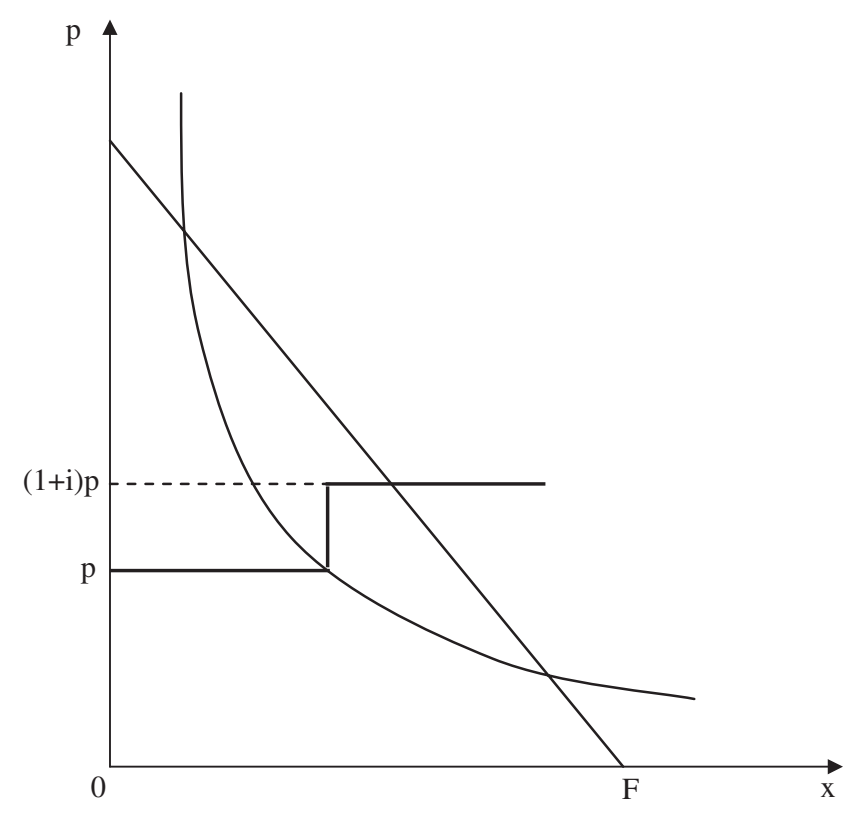

Fig. 8.

the horizontal summation of all importers' marginal cost functions (derived from (4)) is the thick line shown in Fig. 8. It is easy to show that in this case $r^{*}=(1+i) p$ is an equilibrium. That is, if each importer charges $r^{*}$ then no one can do better by deviating. To see this note that when everybody charges $(1+i) p$, the profit earned by each importer is given by $i R / m p$. Clearly by undercutting this price, an importer can only do worse. If, on the other hand, an importer charges $r_{i}>(1+i) p$, no one will buy from him. Hence, his profit will drop to zero.

The analysis in the previous paragraph indicates that, for any $p$ and $i$ that satisfy the conditions described above, the profits of the firm and the bank are identical with or without the designated importers. Also, consumers face the same marginal price and demand the same amount of the good in the two cases. A similar equivalence can be shown for other combinations of $p$ and $i$. Since we focus on the welfare consequences of the strategic interaction between the firm and the bank, this equivalence allows us to ignore the importers in our analysis.

\section{Policy implications}

The model and the results described in this paper have important policy implications. First, it cautions aid donor agencies not to presume that subsidized credit, given to a Third World nation, necessarily benefits the recipient relative to the case in which credit is made available by a profit-maximizing bank or financial 
institution. At first sight it seems that the availability of subsidized credit cannot make the recipient nation worse off. However, we have shown that, depending on the structure of the import market, the advantages of subsidized credit may flow into the hands of corporations that sell goods to the recipient nations. In such a situation the donor agency has to think of ways, other than subsidized credit, for reaching benefit to nations. The classical literature on aid-tying used to be concerned with this question. What we have shown in this paper, however, is that the flow-back of benefit to the North can occur even when aid is not tied, but depending on the market structure of imports and the strategic position of the donor.

In trying to reach out to poor nations, most international organizations use the method of lowering interest rates. The IMF uses this for the most indebted and poor nations, while combining the generous loan terms with 'conditionalities', which pertain to macroeconomic policies such as the need to keep the fiscal deficit under control and money supply growth in check. What this paper alerts us to is the fact that such policies may not be enough to plug the holes through which the benefits of cheap credit get frittered away. The 'market structure' of trade may be the main route through which the immiserization occurs. Hence, before lending at concessional rates, it is worth examining and advising recipient governments on the channels and structure of trade and methods of releasing limited foreign exchange reserves.

The model suggests (though we have not really gone into this) that there may be advantages to the South of giving the import rights to a single agent. This would empower the importers vis-à-vis the Northern manufacturer and may end up benefiting the Southern consumer. Secondly, the Southern government may stand to gain by being more pro-active in the foreign exchange market. Releasing the foreign exchange as quotas to different agents may not be a good idea.

Let us take up the first point first. In our model the Southern importers do poorly because they compete against one another both in the product market and the international credit market. If they could behave collusively, they could exercise market power. However, collusive behavior is difficult to sustain on its own - a point made persuasively in the context of international borrowing by governments by Fernandez and Glazer (1990). However, in our model since the borrowers are agencies within a nation, the government can enable them to exercise market power. The system of 'canalized' imports used by some nations, for instance, India, could have potentially played this role. In practice, canalized imports have been inefficient and bureaucratically cumbersome. Its potential has not been understood, let alone realized.

Let us now turn to the second subject of how to ration the limited foreign exchange reserve. The method analyzed in this paper-namely, one where the foreign exchange is rationed out to the importers - is not the only one. The government could (and they often do) place quantity restrictions on the amount each importer may import. The analysis of this is not trivial since, while each importer will of course take the quantity ration as given, the government should be modeled as choosing that quantity ration, given which the total import value equals the amount of foreign exchange the government has (or wants to release). There can be other 
more sophisticated kinds of rationing, for instance one in which the amount of foreign exchange released to an importer could depend on the terms of trade. Each such ration will change the market outcome and the total benefit generated to the South and may even avert the paradox of benevolence. In the future it will be worth examining formally the welfare effects of different systems of releasing limited foreign exchange and for the Southern government to choose a system consciously to maximize the welfare of its consumers.

\section{Acknowledgements}

We are grateful to Abhijit Banerjee, Jonathan Eaton, Raquel Fernandez, Arvind Panagariya, Priya Ranjan, Debraj Ray, Henry Wan and the participants of a conference at the University of California, Irvine, where the paper was presented. The paper also benefited greatly from the comments of an anonymous referee and an Associate Editor.

\section{Appendix A}

Proof of the Proposition. We first analyze the firm's best response given $i(\geqslant 0)$ chosen by the bank.

First consider $i$ that satisfies

$$
i \geqslant \frac{a^{2}-4 b R}{4 b R} \text {. }
$$

Under (A.1), the South does not borrow any hard currency for any $p$ chosen by the Northern firm. To see this, note that (A.1) is equivalent to ' $R \geqslant p[a-(1+i) p] / b$ holds for all $p$.' Given such $i$, the firm chooses $p$ such that the South spends $R$ units of hard currency to purchase the good; namely it chooses $p$ such that $p[(a-p) / b]=R$ holds. Hence, the firm's best response is given by

$$
p=\frac{a+\sqrt{a^{2}-4 b R}}{2} \equiv p^{B} .
$$

Any $(p, i)$ such that $p=p^{B}$ and $i \geqslant\left(a^{2}-4 b R\right) / 4 b R$ is a Nash equilibrium. Graphically, in this Nash equilibrium the firm chooses the price that corresponds to point $B$ in Fig. 3 and the bank chooses high enough $i$ so that $a^{\prime} F$ does not intersect the rectangular hyperbola twice. In this equilibrium (we call it $B$-equilibrium), the bank's profit is zero and the firm's profit is given by

$$
\frac{\left(p^{B}-c\right)\left(a-p^{B}\right)}{b} \equiv \pi^{B} \text {. }
$$

Next consider $i$ that satisfies

$$
i<\frac{a^{2}-4 b R}{4 b R} \text {. }
$$


Consider the monopolist who faces the demand curve given by $p=(a-b x) /(1+i)$. It charges the price given by (A.5) and the quantity demanded is given by (A.6):

$$
\begin{aligned}
& p=\frac{a+(1+i) c}{2(1+i)} \equiv \tilde{p}, \\
& x=\frac{a-(1+i) c}{2 b} \equiv \tilde{x} .
\end{aligned}
$$

Note that the Northern firm can earn $\pi^{B}$ by choosing $p=p^{B}$ regardless the value of $i$ chosen by the bank. Then, given $i$, the firm chooses $\tilde{p}$ if and only if $\tilde{\pi} \equiv(\tilde{p}-c) \tilde{x} \geqslant \pi^{B}$. Hence the Northern firm's reaction function is given by

$$
p(i)= \begin{cases}\frac{a+(1+i) c}{2(1+i)} \equiv \tilde{p} & \text { if } \tilde{\pi} \geqslant \pi^{B} \\ \frac{a+\sqrt{a^{2}-4 b R}}{2} \equiv p^{B} & \text { otherwise. }\end{cases}
$$

Next we analyze the bank's best response given that the firm chooses $p$ that satisfies

$$
p[(a-p) / b]>R .
$$

Given such price, the demand given by the unconstrained demand schedule (which is $p=a-b x)$ is not feasible unless the bank sets $i=0$. The bank chooses $i$ that maximizes its profit given by

$$
\Pi(i) \equiv i\left\{p\left[\frac{a-p(1+i)}{b}\right]-R\right\} .
$$

Note that, given (A.8), the bank can choose $i>0$ such that $\Pi(i)>0$. The standard maximization exercise then implies that the bank's best response is given by

$$
i(p)=\frac{p a-p^{2}-b R}{2 p^{2}} .
$$

Now we characterize a Nash equilibrium in which the bank lends a strictly positive amount of hard currency to the South. Insert (A.10) into (A.5), and we obtain

$$
f(p) \equiv 2 p^{3}-c p^{2}-(2 b R+a c) p+b c R=0 .
$$

Note that $f(0)=b c R \geqslant 0$ and $f(c)=c^{2}(c-a)-b c R \leqslant 0$. This means that (A.11) has exactly one root that is strictly greater than $c$. We denote the root by $p^{*}$. If there exists a Nash equilibrium in which the bank lends a strictly positive amount of hard currency to the South, such equilibrium is characterized by $(p, i)=\left(p^{*}, i\left(p^{*}\right)\right)$. This constitutes a Nash equilibrium of the game if and only if $(p, i)=\left(p^{*}, i\left(p^{*}\right)\right)$ satisfies $\tilde{\pi} \geqslant \pi^{B}$ and (A.8); or equivalently if (A.12) and (A.13) hold:

$$
\frac{\left[a-\left(1+i\left(p^{*}\right)\right) c\right]^{2}}{4 b\left(1+i\left(p^{*}\right)\right)} \geqslant R-\frac{c\left(a-\sqrt{a^{2}-4 b R}\right)}{2 b},
$$




$$
p^{*}\left[\left(a-p^{*}\right) / b\right]>R .
$$

Note that $p^{*}$ is continuous in $c$, which implies that $i\left(p^{*}\right)$ is also continuous in $c$.

Let $c=0$. Then $f(p)=2 p^{3}-2 b R p$, and so $p^{*}=\sqrt{b R}$ and $i\left(p^{*}\right)=$ $(a \sqrt{b R}-2 b R) / 2 b R$. We find that, when $c=0$, (A.12) is equivalent to $a \geqslant 2 \sqrt{b R}$ and (A.13) is equivalent to $a>2 \sqrt{b R}$. Note that Assumption 1 implies $a>2 \sqrt{b R}$ holds when $c=0$, and that both $p^{*}$ and $i\left(p^{*}\right)$ are continuous in $c$. This implies that there exists $c^{*}(>0)$ such that both (A.12) and (A.13) hold for all $c \in\left[0, c^{*}\right]$.

Next, we assume $c \in\left[0, c^{*}\right]$, and let $W^{\pi}$ denote South's aggregate welfare in the Nash equilibrium represented by $\left(p^{*}, i\left(p^{*}\right)\right)$. As stated in the text, the social welfare is represented by the area $S T Q \hat{p} a$ in Fig. 6, which is given by

$$
W^{\pi}=(1 / 2)\left[a-\left(1+i\left(p^{*}\right)\right) p^{*}\right] x^{*}+i\left(p^{*}\right) R,
$$

where $x^{*} \equiv\left(a-\left(1+i\left(p^{*}\right)\right) p^{*}\right) / b$. When $c=0$, we have

$$
W^{\pi}=\frac{a^{2}}{8 b}+\frac{\sqrt{b R}(a-2 \sqrt{b R})}{2 b}>W^{b}=\frac{a^{2}}{8 b},
$$

where strict inequality holds because $a>2 \sqrt{b R}$ by Assumption 1. Note that $p^{*}, i\left(p^{*}\right)$ and $x^{*}$ are all continuous in $c$. This implies that there exists $c^{* *}>0$ such that $W^{\pi}>W^{b}$ holds for all $c \in\left[0, c^{* *}\right]$. Finally, let $\tilde{c} \equiv \operatorname{Min}\left[c^{*}, c^{* *}\right]$, and we obtain the desired result.

\section{References}

Anant, T.C.A., Basu, K., Mukherji, B., 1995. A model of monopoly with strategic government intervention. Journal of Public Economics 57, 25-43.

Bardhan, P., 1984. Land, Labor, and Rural Poverty. Columbia University Press, New York.

Basu, K., 1991. The international debt problem, credit rationing, and loan pushing: Theory and evidence. Princeton Studies in International Finance, No. 70.

Basu, K., 1993. Lectures in Industrial Organization Theory. Blackwell Publishers, Oxford.

Baysan, T., 1992. Trade policies in Pakistan. In: Salvatore, D. (Ed.), National Trade Policies, Handbook of Comparative Economic Policies, vol. II. Greenwood Press, New York.

Ben-David, D., 1993. Equalizing exchange: Trade liberalization and income convergence. Quarterly Journal of Economics 108, 653-679.

Bhaduri, A., 1983. The Economic Structure of Backward Agriculture. Academic Press, London.

Bhagwati, J., 1970. The tying of aid. In: Bhagwati, J., Eckaus, R. (Eds.), Foreign Aid. Penguin Books, Harmondsworth.

Burnside, C., Dollar, D., 2000. Aid, policies, and growth. American Economic Review 90, 847-868.

Collier, P., 1997. The failure of conditionality. In: Gwin, C., Nelson, J.M. (Eds.), Perspectives on Aid and Development. Johns Hopkins University Press, Baltimore, MD.

Darity Jr., W., Horn, B., 1988. The Loan Pushers: The Role of the Commercial Banks in the International Debt Crisis. Ballinger, Cambridge, MA.

Deshpande, A., 1999. Loan pushing and triadic relations. Southern Economic Journal 65, 914-926.

Eaton, J., 1989. Foreign public capital flows. In: Chenery, H., Srinivasan, T.N. (Eds.), Handbook of Development Economics, vol. 2. North-Holland, Amsterdam.

Fernandez, R., Glazer, J., 1990. The scope for collusive behavior among debtor countries. Journal of Development Economics 32, 297-313. 
Fleisig, H., Hill, C., 1984. The benefits and costs of official export credit program. In: Baldwin, R.E., Krueger, A.O. (Eds.), The Structure and Evolution of Recent U.S. Trade Policy. University of Chicago Press, Chicago.

Frankel, J., Romer, D., 1999. Does trade cause growth? American Economic Review 89, 379-399.

Gwyne, S.C., 1983. Adventures in the loan trade. Harper's Magazine, September, 22-26.

Hansen, H., Tarp, F., 2001. Aid and growth regressions. Journal of Development Economics 64, 547-570.

Hyson, C.D., Strout, A.M., 1968. Impact of foreign aid on U.S. Exports. Harvard Business Review 46, $63-71$.

IMF, 2001a. Structural conditionality in fund-supported programs, http://www.imf.org/external/np/pdr/ cond/2001/eng/struct/index.htm.

IMF 2001b. Trade policy conditionality in fund-supported programs, http://www.imf.org/external/np/ $\mathrm{pdr} / \mathrm{cond} / 2001 / \mathrm{eng} / \mathrm{trade} /$ index.htm.

OECD 2001. Export Credit Financing Systems. OECD, Paris.

Sachs, J.D., Warner, A., 1995. Economic reform and the process of global integration. Brookings Papers on Economic Activity 1, 1-118.

Taylor, L., 1985. The theory and practice of developing country debt: an informal guide for the perplexed. Journal of Development Planning 16, 195-277.

Winkler, M., 1929. Investments of US Capital in Latin America. World Peace Foundation Pamphlets, Boston. 